\title{
In Vivo Model of Small Intestine
}

\section{Maxime M. Mahe, Nicole E. Brown, Holly M. Poling, and Michael A. Helmrath}

Takashi Tsuji (ed.), Organ Regeneration: 3D Stem Cell Culture \& Manipulation, Methods in Molecular Biology, vol. 1597, DOI 10.1007/978-1-4939-6949-4_17, @ S Springer Science+Business Media LLC 2017

DOI 10.1007/978-1-4939-6949-4_18

The published version of this book included the incorrect juxtaposition of two of the chapter authors' names. The names have been corrected as follows:

Maxime M. Mahe and Michael A. Helmrath 